\title{
Provision of Advanced Care Planning Information by Public INSTITUTIONS OF Higher EdUCATION IN THE U.S.
}

\author{
Katherine A. Chiu, BS \\ Dayna S. Henry, PhD, MCHES \\ Michael J. Klein, PhD
}

\begin{abstract}
This study explored how many, and in what form, U.S. public institutions of higher education (IHE; $n=1,642)$ provide information regarding advance care planning $(A C P)$, advance care directives $(A C D s)$, and end-of-life (EOL) care on their official websites. Chi-square analysis was used to examine relationships between the availability of information and three institutional characteristics (size, type, and medical degree offering). Results show that most public IHE $(92.1 \%, n=1,513)$ do not provide any information regarding ACDs or ACP on their websites. Overall, large, four-year institutions that offer medical degrees were significantly more likely to provide ACP and ACD information on their official websites.
\end{abstract}

Keywords: advance care directives, advanced care planning, end of life care, higher education, health promotion

\section{INTRODUCTION}

Advance care planning (ACP) is a long, reflective process that requires individuals to grapple with their medical preferences and initiate difficult conversations with their loved ones. Though $\mathrm{ACP}$ can be challenging, it is essential to ensuring a patient's end-of-life (EOL) care is carried out according to their wishes (Gaster et al., 2017; National Institutes of Health, 2018). A key element of ACP is preparing an advance care directive (ACD), which typically includes three sections: a living will, durable power of attorney for health care (DPAHC), and do not resuscitate (DNR) order (Hinders, 2012; Sudore et al., 2013). The benefits of completing an ACD extends beyond the individual patient, and gives a sense of peace and confidence to all those caring for them. This is especially true for acute, medical emergencies; however, ACDs have also proven beneficial for those living with severe chronic conditions, such as cancer (Lyon et al., 2013). In both urgent and non-urgent situations, an ACD acts as a set of instructions that dictates who can make decisions on their behalf and what medical treatments are desired. This is particularly useful in situations where the patient is incapacitated and unable to communicate. When this occurs, it is virtually impossible for a patient to have agency in their healthcare decision-making without an ACD. Even if an ACD does not explicitly state the patient's wishes for a specific situation, their DPAHC can act as their advocate and decision maker.

The right to complete an ACD is largely protected by two pieces of legislation and the four foundational bioethics principles: autonomy, nonmaleficence, beneficence, and justice (Beauchamp \& Childress, 1979; Hinders, 2012). In 1990, the Patient Self-Determination Act encouraged patients to take agency in their medical decisions and proactively decide on the type and extent of medical care they would hope to have in an emergency (101st Congress, 1990; Gerontological Advanced Practice Nurses Association, 2020). Seven years later, President Clinton appointed the Advisory Commission on Consumer Protection and Quality in the Health Care Industry to recommend necessary measures for promoting health care quality (President's Advisory Commission on Consumer Protection and Quality in the Health Care Industry, 1998). As a result, the Consumer Bill of Rights and Responsibilities was created to encourage active participation in improving personal health status. These are often modified to fit the specific values of individual healthcare organizations; however, most explicitly mention the right and responsibility to create and revise an ACD, and have these wishes honored (Johns Hopkins Medicine, 2020b). Together, these pieces of legislation safeguard basic rights and protections that are available to all patients, regardless of age, morbidity, or perceived risk of death. Although these patient protections are still relatively young, it is important to promote them and encourage all patients to take advantage of the benefits they provide.

Unfortunately, many reports indicate that less than $30 \%$ of all adults living in the U.S. have completed an ACD (Hickman et al., 2005). A

Corresponding Author: Dayna Henry, Ph.D., 235 Martin Luther King Jr Way, Harrisonburg, Virginia 22807, MSC 4301, Phone: 540-568-4166, E-mail: henryds@jmu.edu 
recent study confirms that, over a decade later, the number of adults with ACDs has staggered around one in three (Kuldeep et al., 2017). This number is relatively small compared to the $88 \%$ of hospice patients (Jones et al., 2011), and 47\% of adults over the age of 60 (American Association of Retired Persons, 2008), who have completed their ACDs. This pattern suggests the likelihood of ACD completion increases with age and morbidity. Moreover, it indicates there is a public misconception that ACP is only necessary for elderly, disabled, and chronically ill populations (Niebuhr et al., 2014). However, ACD completion is beneficial for protecting the autonomy of any individual over the age of 18 (Hinders, 2012; Kavalieratos et al., 2015). Researchers at the University of Texas at Austin found that $98 \%$ of a 147 -student sample had not completed an ACD, and $83 \%$ had never considered it necessary (Schnur \& Radhakrishnan, 2019). This is in contrast to the $85 \%$ who claimed to support ACP (Schnur \& Radhakrishnan, 2019). In addition, a study at James Madison University found that $26.9 \%$ of a 360 -student sample had previously heard of ACP, but only 5\% had completed an ACD Chiu \& Topf, 2019. These findings confirm that ACP has traditionally focused on elderly and aging populations, creating a lack of ACP awareness and ACD completion among college student populations (Niebuhr et al., 2014; Sanders \& Robinson, 2017; Schnur \& Radhakrishnan, 2019).

In order to combat low ACD completion, researchers have sought to better understand what barriers exist. One study found that the most common self-reported barrier for patients over the age of 50 was perceiving ACP as irrelevant (Schickedanz et al., 2009). However, the novel coronavirus pandemic (COVID-19) has renewed the importance of preparing such documentation (Borzykowski, 2020). Since the first case of COVID-19 was confirmed in the U.S. on January 21, 2020 (American Journal of Managed Care Staff, 2020), there have been thousands of confirmed deaths and the number of cases continue to rise (Roser et al., 2020). It has claimed the lives of young and old, as well as those who were fairly healthy and those who had preexisting conditions (Johns Hopkins Medicine, 2020a). The COVID-19 pandemic has made the reality of death quite transparent to all, and introduces a more pressing need for young adults to engage in ACP. Prior to the pandemic, the majority of college students had never thought about their own death or the necessity for an ACD (Thoelke, 2018). As COVID-19 persists in the U.S. without a clear end in sight, it becomes more important now than ever to increase ACP awareness and ACD completion among college students.

Even though many young adults may not choose to engage in ACP in the immediate future, having prior knowledge and exposure to this information can help them recognize ACP as a beneficial health behavior when their perceived seriousness and susceptibility increases (Kavalieratos et al., 2015). For college students, the most significant barrier to ACD completion is a lack of information (Kavalieratos et al., 2015). This problem cascades from the administrative level of institutions of higher education (IHE) and leaves college students at a disadvantaged position in not only developing their medical autonomy, but also planning for possible EOL care (Kapp, 2000). Unless they have participated in the process with their family, most students do not have prior experience with ACP (Tripken \& Elrod, 2018). It is also extremely unlikely for students to be introduced to this process during enrollment at their IHE, as most only require standard information, such as medical history, current medications, allergies, and proof of immunizations (Kapp, 2000). From a health promotion perspective, this becomes exponentially more problematic when an IHE is recognized as an anchor institution. IHE with this classification commit significant resources to their surrounding communities, and often play a large role in promoting health equity (Koh et al., 2020; National Academy of Sciences, 2018). As such, these IHE are frequently used as reliable and prominent sources of information, and have a responsibility share useful information with their stakeholders.

Students and their guardians as well as IHE administrators and healthcare professionals all share the responsibility of promoting ACP as a necessary health behavior. In addition to a lack of information, insufficient education and training for healthcare professionals are major barriers to young adults engaging in ACP (Hughes et al., 2018). According to the National Center for Education Statistics, 90\% of students attending public IHE are under the age of 25 (National Center for Education Statistics, 2020). Given their young age, many college students experience an adjustment period, where they become acclimated to their increased independence and responsibility. As such, healthcare decision-making can be an unfamiliar territory for young adults, especially those who are not affected by severe medical conditions and have not experienced a medical emergency before. In fact, college students rely most heavily on their parents and guardians for health information, and they place high levels of trust in medical staff and health educators (Vader et al., 2011). In order for students to take a higher degree of responsibility in their healthcare, and for IHE to adequately address student questions and concerns, both patients and providers need to have a greater awareness and understanding of ACP (Levi et al., 2013; Nash et al., 2016; Wiener et al., 2013). A very promising way in which this can be achieved is through more effective health information campaigns (Vader et al., 2011; Woodlen \& Bakken, 2016). However, it is unknown how many IHE provide such information to their students. Therefore, the purpose of this study was to determine how many, and in what form, public IHE provide publicly available information regarding ACP, ACD, and EOL care on their official websites. 
Sample

\section{METHOD}

The Carnegie Classification of Institutions of Higher Education (CCIHE) was used to identify public IHE in the U.S. and classify them based on their size, type, and whether they offer medical degrees. According to the 2015 CCIHE data file, there were a total of 1,644 public IHE in the U.S. at the time of data collection (Carnegie Classification of Institutions of Higher Education, 2018). Upon further inspection, two public IHE were found to be no longer open for enrollment, and were subsequently removed from the sample. Thus, there were a total of 1,642 institutions in the final sample $(n=1,642)$. The official website of each public IHE was first used to determine whether they provide information about ACDs or ACP that can be accessed by the general public. If relevant information was found, it was further examined for its contents and method of delivery. This research was exempt from institutional review board approval because all data collection was obtained through publicly available sources and did not involve human subjects.

\section{Design}

On each IHE's official website, the search utility was used to conduct three separate searches of the following key words: advance care directive, advance care planning, end of life care. Though uncommon, some IHE websites did not have search utilities. In these instances, a manual search of the website was conducted on all webpages where relevant information might be located (e.g., health center, academic departments, etc.). When there were no results for a given search term, the data was coded as "0." When there were results, the primary investigator reviewed each result to determine whether the information was publicly accessible and relevant to the search term. Once these criteria were verified, the data was coded as "1." In order to understand the information that was being provided, the primary investigator also took notes in descriptive text form. For further analysis, the CCIHE data file was also used to categorize IHE based on their size (small, medium, large, or exclusively graduate), type (two-year, four-year, or exclusively graduate), and whether they offer medical degrees (Table 1).

\section{Analysis}

Data was coded and analyzed using SPSS. Descriptive analyses and Chi-square $\left(X^{2}\right)$ tests of independence were used to examine whether there was a relationship between three institutional characteristics (size of institution, type of institution, and medical degree offering) and the availability of ACD, ACP, and EOL care information. This was performed with a $\mathrm{p}$ value at the $\leq$ .05 level.

\section{RESULTS}

An overwhelming majority of public IHE do not provide any information regarding ACDs, ACP, or EOL care on their official websites (Table 2). When searched, the term advance care directive only appeared on $7.5 \%(n=123)$ of public IHE websites. Advance care planning only ap-

Table 1: Characteristics of sampled institutions $(\mathrm{N}=1,642)$

\begin{tabular}{lll}
\hline Characteristic & $\mathbf{n}$ & $\%$ \\
\hline Size & & \\
\hline Small & 557 & 33.9 \\
\hline Medium & 590 & 35.9 \\
\hline Large & 477 & 29.0 \\
\hline Type of Institution & & \\
\hline Two-year & 926 & 56.4 \\
\hline Four-year & 698 & 42.5 \\
\hline Exclusively graduate & 18 & 1.1 \\
\hline Offers Medical Degree & & \\
\hline Yes & 104 & 6.3 \\
\hline No & 1538 & 93.7 \\
\hline
\end{tabular}

Note. CCIHE does not explicitly describe the size or type of institutions that exclusively offer graduate or professional degrees. 
Chiu, Henry, Klein

peared on $3.3 \%(n=55)$, and even less, end of life care on only $1.8 \%(\mathrm{n}=30)$. In other words, there were no results for advance care directive on $92.5 \% \quad(n=1519)$ of public IHE websites, no results for advance care planning on $96.7 \%$ $(\mathrm{n}=1587)$, and no results for end of life care on $98.2 \%(n=1612)$. Most of the time, IHE that provided information on ACDs also provided information on ACP ( $n=49$ out of 55; Table 2). Therefore, there were only $129(7.9 \%)$ unique public IHE that provided information on either ACD or ACP, or both (Table 2). For analysis purposes, these IHE are noted as those that provided information on "ACD or ACP" (Table 2). Chi-square analysis revealed significant relationships between all three IHE characteristics and the availability of ACD or ACP information. This indicates that the size of institution $\left(X^{2}(3)=56.24, \mathrm{p}<.01\right)$, type of institution $\left(X^{2}(2)=118.70, \mathrm{p}<.01\right)$, and medical degree offering $\left(X^{2}(3)=56.24, \mathrm{p}<.01\right)$ all impact the likelihood of an IHE providing publicly available information on these topics. Overall, large, four-year institutions that offer medical degrees are significantly more likely to provide information pertaining to either ACD or ACP on their official websites (Table 3).

\section{Commonly Provided Resources}

The majority of IHE that had publicly available information on their official websites provided a list of Patient Rights and Responsibilities. The University of Southern Mississippi, Massachusetts College of Liberal Arts, and Salisbury University are just a few of the many institutions that have made this list accessible to the general public. This list communicates a variety of useful information; however, it does not provide in-depth instruction or guidance specifically related to ACD completion. Institutions with more comprehensive information included definitions of key terminology, internal or external resources, and explicit directions for how to complete an ACD. For instance, Georgia Institute of Technology provides an overview of ACDs, brief answers to frequently asked questions, and a detailed explanation of their Health Services policy and protocol related to ACDs (Georgia Institute of Technology, 2020). This helps any students, faculty, or staff utilizing their services understand what to expect and what their staff is willing or able to assist with.

\section{Notable Institutions}

Colorado State University has created the Larimer Advance Care Planning Team, which provides free guidance on how to have discussions with loved ones, express medical wishes in writing, and customize life-sustaining treatment preferences (Senior Access Points of Larimer County, 2020). Though their services are available to the community at-large, they are available to any person that is 18 years or older. Their team focuses on creating a plan that represents the individual's values and are available to any person that is 18 years or older. University of Minnesota, University of North Carolina-Charlotte, and Western Washington University also offer workshops about ACP. Those offered by University of Minnesota are noteworthy because they can be easily requested for off-campus groups by employers, human resources directors, clinic administrators, churches, and community organizations through an online form (University of Minnesota, 2020). Topics covered during this one-hour workshop range from key ACP terminology to ACD policies and practices specific to Minnesota. Another institution that stands out among others is University of Maryland. Their University Health Center has a website dedicated to providing information to the parents of incoming students. Among their reminders to submit immunization records and complete annual insurance waivers is a recommendation to consider discussing ACDs with students (University of Maryland, 2020). This recommendation increases parental knowledge and associates ACD completion with starting college.

\section{Unique Resources Provided by Institutions with Medical Schools}

Some of the most comprehensive ACD resources were found on the official websites of IHE that have a medical center or hospital affiliation. For instance, the University of Missouri provides detailed descriptions of each type of ACD and explores the common controversies or challenges associated with ACD completion (University of Missouri, 2020). The distinctive aspect of their website is that they also list situations and specific healthcare interventions that patients should con-

Table 2: Descriptive Results for ACD, ACP, or EOL Care

\begin{tabular}{lllllllll}
\hline Search Term & \multicolumn{2}{l}{$\begin{array}{l}\text { Advance care } \\
\text { directive }\end{array}$} & \multicolumn{2}{c}{$\begin{array}{l}\text { Advance care plan- } \\
\text { ning }(\text { ACP) }\end{array}$} & ACD or ACP & \multicolumn{2}{l}{$\begin{array}{l}\text { End of life (EOL) } \\
\text { care }\end{array}$} \\
\hline & $\mathrm{n}$ & $\%$ & $\mathrm{n}$ & $\%$ & $\mathrm{n}$ & $\%$ & $\mathrm{n}$ & $\%$ \\
\hline Information & & & & & & & & \\
Yes & 123 & 7.5 & 55 & 3.3 & 129 & 7.9 & 30 & 1.8 \\
No & 1519 & 92.5 & 1587 & 96.7 & 1513 & 92.1 & 1612 & 98.2 \\
\hline
\end{tabular}


Table 3: Availability of information by characteristics of institutions $(N=1,642)$

\begin{tabular}{|c|c|c|c|c|}
\hline & \multicolumn{2}{|c|}{$\begin{array}{l}\text { ACD or ACP } \\
\text { information available }\end{array}$} & \multicolumn{2}{|c|}{$\begin{array}{l}\text { No ACD or ACP } \\
\text { information available }\end{array}$} \\
\hline & $\mathrm{n}$ & $\%$ & $\mathrm{n}$ & $\%$ \\
\hline \multicolumn{5}{|l|}{ Size $^{\star}$} \\
\hline Small & 15 & 2.7 & 542 & 97.3 \\
\hline Medium & 40 & 6.8 & 550 & 93.2 \\
\hline Large & 72 & 15.1 & 405 & 84.9 \\
\hline Exclusively graduate & 2 & 11.1 & 16 & 88.9 \\
\hline \multicolumn{5}{|l|}{ Program Length ${ }^{\star}$} \\
\hline Two-year & 14 & 1.5 & 912 & 98.5 \\
\hline Four-year & 113 & 16.2 & 585 & 83.8 \\
\hline Exclusively graduate & 2 & 11.1 & 16 & 88.9 \\
\hline \multicolumn{5}{|c|}{ Offers Medical Degree } \\
\hline Yes & 49 & 47.1 & 55 & 52.9 \\
\hline No & 80 & 5.2 & 1458 & 94.8 \\
\hline
\end{tabular}

${ }^{\star} \chi 2$ significant at $\mathrm{p}<.01$

sider when dictating their wishes. Virginia Commonwealth University provides a comprehensive list of questions that various audiences may have, such as those that are young, have children, are married, or have limited medical knowledge (Virginia Commonwealth University, 2020). In addition, their website lists numerous national programs that exist to help with the process of ACP and ACD completion. They provide external links to Your Right to Decide, Advance Directive Tool Kit, Dying with Dignity: Medical Treatment, Caring Connections, and Five Wishes. These national resources are specialized, comprehensive, and guaranteed to have the most accurate and up-todate information regarding ACDs. With these resources readily available, IHE are not expected to create new content for communicating with students about ACD completion. However, there are still a select few that employ their own resources to promote ACD awareness and completion.

\section{DISCUSSION}

The results of this study confirm there is a significant lack of information about ACD and ACP available on the official websites of public IHE. This raises a major concern that IHE are not actively educating or raising awareness about the importance of ACD completion. More importantly, a lack of information on official websites may be indicative of the institutions own lack of awareness, training, and understanding of the process. Many institutions that provided online information accomplished this through a list of
Patient Rights and Responsibilities. This list does not explore ACDs or ACP in-depth; however, is beneficial because it raises student consciousness of what resources are available to them as well as what expectations there are of them as patients (President's Advisory Commission on Consumer Protection and Quality in the Health Care Industry, 1998). Considering most students do not have experience managing their healthcare prior to college, they will likely need substantial guidance navigating the world of medicine. Despite their utility, the list of Patient Rights and Responsibilities are the bare minimum for what should be provided. This list alone is not sufficient for increasing awareness and understanding of the purpose of ACP and the value in ACD completion.

The institutions that provide no information, or solely provide a list of Patient Rights and Responsibilities, should take note of the ways in which other institutions have chosen to present this information. It is clear that IHE that are larger or offer medical degrees are more likely to provide ACD and ACP information on their websites. This may result from differences in resource allocation, institutional goals, or professional training. For instance, Colorado State University is unique in their creation of the Larimer Advance Care Planning Team. Their interest and capacity to provide this resource to their students may be directly related to their medical school affiliation. However, most IHE that offer medical degrees redirect their students to external resources and national programs in order to provide the most accurate 
Chiu, Henry, Klein

information. Employing this technique may be particularly beneficial for IHE that do not have access to specialized centers, programs, or personnel that focus on increasing ACD awareness and completion. Two external resources that have been repeatedly cited for their ability to increase patient awareness and adolescent readiness are Five Wishes and Voicing My CHOiCES (Thoelke, 2018; Wiener et al., 2010; Wiener et al., 2012; Zadeh et al., 2014).

IHE should look to Colorado State University, University of Minnesota, Georgia Institute of Technology, and Virginia Commonwealth University for guidance in developing a variety of ongoing programs and online materials that will best serve their students. These institutions are redefining standards for engaging students in ACP and can offer insight to those that want to follow suit. Moreover, IHE should pay special attention to University of Maryland for their approach to associating ACD completion with the college student onboarding process. Although many IHE only required medical histories and vaccination records (Kapp, 2000), University of Maryland uniquely introduces $\mathrm{ACD}$ s to incoming students through their parents and guardians. ACD completion is not required, but their University Health Center encourages parents and guardians to initiate these conversations prior to the student's arrival on campus. As a result, they communicate to parents that ACD completion deserves as much consideration and deliberation as the other tasks they must complete. Existing literature reports that a lack of information regarding ACP creates barriers to ACD completion (Kavalieratos et al., 2015), and young students are unlikely to seek this information on their own. By initiating these conversations concurrently with student onboarding and the onset of adulthood, there is immense potential for increasing student awareness.

Of the few IHE that provided information on their websites, many emphasized planning ahead and engaging in the ACP process as early as possible. Regardless of age, ACDs promote patient autonomy in EOL care and alleviate stress for the patient, family, and healthcare providers involved (Hinders, 2012; Sudore et al., 2013). Traditional undergraduate students who begin college after high school are at least 18 years of age or will reach such age during their studies. Inevitably, they will need to start making decisions for themselves, especially in the context of healthcare. At the age of 18 , students no longer require permission from parents or guardians to receive medications, procedures, and treatments. They become the primary contact for their private medical information and records. With this new sense of autonomy and independence, students must take charge of their healthcare decisions. IHE that acknowledge the significance of this personal milestone and provide resources for their adjustment will better prepare students for future situations that involve difficult medical decisions.

In addition to the significance greater health promotion efforts would have for college students, anchor institutions can have a broader impact on their local communities. These IHE are well-suited to raise ACP awareness and ACD completion among all people over the age of 18 . Approximately one in three U.S. adults have completed their ACDs (Kuldeep et al., 2017), and anchor institutions should take more responsibility to increase this number. Anchor institutions are known to have powerful social impacts on their communities, and community-based solutions play a major role in improving health equity and well-being (National Academy of Sciences, 2018). One substantial component to health equity is the accessibility of health information. As such, more IHE should be dedicated to raising awareness of ACD completion as a beneficial health behavior, making ACP information and resources accessible to the general public, and collaborating with community partners to promote and execute these resources. Colorado State University is an excellent example of an IHE that has developed partnerships with several community partners in order to establish and promote the resources available through the Larimer Advance Care Planning Team.

\section{Limitations and suggestions for future research}

This study was limited by the lack of prior research on the amount and type of ACD or ACP information available on public institutions' official websites. In absence of existing literature that explored this topic, it was difficult to determine the best method for conducting this research. In addition, data collection was performed solely by the primary investigator, which may lead to observer error. This research could have been strengthened by having multiple investigators cross-check search results. However, given the exploratory nature of the study, it was deemed acceptable to have one researcher code all data for consistency.

Future studies should perform a comparative analysis of the resources created by IHE, such as the workshops at University of Minnesota and the Larimer Advance Care Planning Team at Colorado State University. This assessment should compare the quality and effectiveness of these resources in order to inform future decisions made by IHE. It should also focus on the accessibility of not only the IHE resource itself, but also the information provided to participants within those resources. Although sufficient institutional awareness is still needed to increase the number of IHE that provide publicly available resources, this research could help determine what format is most effective for presenting this information and increasing ACD completion (e.g., group workshop, online information, individual counseling, etc.). It would also be valuable to explore any differences that exist in student ACP awareness and ACD completion at IHE that provided information on their official websites versus those that did not. This could determine whether IHE health promotion efforts effectively increase student knowl- 
edge and engagement in this health behavior. Finally, this study should be replicated to determine whether more IHE have decided to provide publicly available ACP information on their websites in response to the COVID-19 pandemic.

\section{CONCLUSION}

This study found that a very small percentage of public IHE provide information and resources pertaining to ACP on their official websites. This calls for greater awareness and training among individuals working in student affairs and on-campus health centers. Less than one-third of adults living in the U.S. have completed their ACD (Hickman et al., 2005). Therefore, finding creative and convenient ways to engage young adults in the ACP process is crucial. This is particularly relevant in the wake of emerging deadly diseases, such as the novel coronavirus (Borzykowski, 2020). IHE that do not provide information regarding ACP should use Colorado State University, University of Minnesota, Georgia Institute of Technology, and Virginia Commonwealth University as guides for developing informative online content, establishing group-based workshops, and forming teams of personnel that are dedicated to this work. University of Maryland is also a great example of how ACD completion can be incorporated into the college student onboarding process. Ideally, IHE should adopt an approach that enhances student awareness, understanding, and access. If more IHE commit to providing information on their websites and acknowledging the importance of these documents, more students will feel confident and prepared to talk about EOL preferences.

\section{References}

101st Congress. (1990, July 2). H.R.4449 - Patient Self Determination Act of 1990. Retrieved from https://www.congress.gov/bill/101st-congress/ house-bill/4449

American Association of Retired Persons. (2008). AARP Bulletin Poll "Getting Ready to Go" Executive Summary. Retrieved from http://assets.aarp. org/rgcenter/il/getting_ready.pdf

American Journal of Managed Care Staff. (2020, November 25). A timeline of COVID-19 developments in 2020. Retrieved from https://www. ajmc.com/view/a-timeline-of-covid19-developments-in-2020

Beauchamp, T., \& Childress, J. (1979). Principles of biomedical ethics. New York: Oxford University Press.

Borzykowski, B. (2020, March 25). Americans rush to make online wills in the face of the coronavirus pandemic. CNBC. Retrieved from https://www. cnbc.com/2020/03/25/coronavirus-pandemictriggers-rush-by-americans-to-make-online-wills. html

Carnegie Classification of Institutions of Higher Education. (2018). Downloads. Retrieved from https://carnegieclassifications.iu.edu/downloads. php
Chiu, K. A. \& Topf, K. G. (2019). Understanding awareness and completion of advanced care directives: An exploratory study. Senior Honors Projects, 2010-2019, 657. https://commons.lib.jmu. edu/honors201019/657.

Gaster, B., Larson, E. B., \& Curtis, J. R. (2017). Advance directives for dementia: Meeting a unique challenge. JAMA, 318(22), 2175-2176. doi: https://doi.org/10.1001/jama.2017.16473

Georgia Institute of Technology. (2020). Advance directives: Your right to decide. Retrieved from https://health.gatech.edu/advance

Gerontological Advanced Practice Nurses Association. (2020). Patient Self-Determination Act (PSDA). Retrieved from https://www.gapna.org/ patient-self-determination-act-psda

Hickman, S. E., Hammes, B. J., Moss, A. H., \& Tolle, S. W. (2005). Hope for the future: Achieving the original intent of advance directives. Hastings Center Report, 35(6), 26-30. doi: https://doi. org/10.1353/hcr.2005.0093

Hinders, D. (2012). Advance directives: Limitations to completion. American Journal Hospice and Palliative Medicine, 29(4), 286-289. doi: https:// doi.org/10.1177/1049909111419293

Hughes, B., O’Brien, M. R., Flynn, A., \& Knighting, K. (2018). The engagement of young people in their own advance care planning process: A systematic narrative synthesis. Palliative Medicine, 32(7), 1147-1166. doi: https://doi. org/10.1177/0269216318772749

Johns Hopkins Medicine. (2020a, December 2). Coronavirus and COVID-19: Younger adults are at risk, too. Retrieved from https://www.hopkinsmedicine.org/health/conditions-and-diseases/ coronavirus/coronavirus-and-covid-19-youngeradults-are-at-risk-too

Johns Hopkins Medicine. (2020b). Patient rights and responsibilities. Retrieved from https://www. hopkinsmedicine.org/patient_care/patient-rightsresponsibilities.html

Jones, A. L., Moss, A. J., \& Harris-Kojetin, L. D. (2011, January). Use of advance directives in longterm care populations (NCHS Data Brief, No. 54). Centers for Disease Control and Prevention. Retrieved from https://www.cdc.gov/nchs/products/databriefs/db54.htm

Kapp, M. B. (2000). Advance medical directives for college students: It's not your father's living will. Journal of American College Health, 49(1), 44-45. doi: https://doi. org/10.1080/07448480009596282

Kavalieratos, D., Ernecoff, N. C., Keim-Malpass, J., \& Degenholtz, H. B. (2015). Knowledge, attitudes, and preferences of healthy young adults regarding advance care planning: A focus group study of university students in Pittsburgh, USA. BMC Public Health, 15(197), 1-7. doi: https:// doi.org/10.1186/s12889-015-1575-y

Koh, H. K., Bantham, A., Geller, A. C., Rukavina, M. A., Emmons, K. M., Yatsko, P., \& Restuccia, R. (2020). Anchor institutions: Best practices to address social needs and social determinants of health. American Journal of Public Health, 
Chiu, Henry, Klein

110(3), 309-316. doi: https://doi.org/10.2105/ AJPH.2019.305472

Kuldeep, N., Gabler, N. B., Cooney, E., Kent, S., Kim, J., Herbst, N., Mante, A., Halpern, S. D., \& Courtright, K. R. (2017). Approximately one in three US adults completes any type of advance directive for end-of-life care. Health Affairs, 36(7), 1244-1251. doi: https://doi.org/10.1377/ hlthaff.2017.0175

Levi, B. H., Wilkes, M., Der-Martirosian, C., Latow, P., Robinson, M., \& Green, M. J. (2013). An interactive exercise in advance care planning for medical students. Journal of Palliative Medicine, 16(12), 1523-1527. doi: https://doi.org/10.1089/ jpm.2013.0039

Lyon, M. E., Jacobs, S., Briggs, L., Cheng, Y. I., \& Wang, J. (2013). Family-centered advance care planning for teens with cancer. JAMA Pediatrics, 167(5), 460-467. doi: https://doi.org/10.1001/ jamapediatrics.2013.943

Nash, W., Mixer, S. J., McArthur, P. M., \& Mendola, A. (2016). The moral courage of nursing students who complete advance directives with homeless persons. Nursing Ethics, 23(7), 743-753. doi: https://doi.org/10.1177/0969733015583926

National Academy of Sciences. (2018). Communities in action: Pathways to health equity. Retrieved from https:/www.nap.edu/resource/24624/ anchor-institutions/

National Center for Education Statistics. (2020, April). Characteristics of postsecondary students. Institute of Education Sciences. Retrieved from https://nces.ed.gov/programs/coe/indicator_csb. asp

National Institutes of Health, National Institute on Aging. (2018, January 15). Advance care planning: Healthcare directives. U.S. Department of Health \& Human Services. Retrieved from https://www.nia.nih.gov/health/ advance-care-planning-healthcare-directives\#what

Niebuhr, B. R., Eames, J., Munsell, D., \& Stephenson, K. S. (2014). Attitudes and beliefs of physician assistant students about advance directives. The Journal of Physician Assistant Education, 25(2), 33-35. doi: https://doi. org/10.1097/01367895-201425020-00009

President's Advisory Commission on Consumer Protection and Quality in the Health Care Industry. (1998, July 17). Consumer Bill of Rights and Responsibilities. Retrieved from https://govinfo. library.unt.edu/hcquality/final/append_a.html

Roser, M., Ritchie, H., Ortiz-Ospina, E., \& Hasell, J. (2020). United States: Coronavirus pandemic country profile. Our World in Data. Retrieved from https://ourworldindata.org/coronavirus/ country/united-states

Sanders, S., \& Robinson, E. L. (2017). Engaging college undergraduates in advance care planning. OMEGA - Journal of Death and Dying, 74(3), 329-344. doi: https://doi. org/10.1177/0030222815598912

Schickedanz, A. D., Schillinger, D., Landefeld, C. S., Knight, S. J., Williams, B. A., \& Sudore, R. L. (2009). A clinical framework for improving the advance care planning process: Start with patients self-identified barriers. Journal of the American Geriatrics Society, 57(1), 31-39. doi: https:/doi. org/10.1111/j.1532-5415.2008.02093.x

Schnur, K., \& Radhakrishnan, K. (2019). Young adult knowledge and readiness to engage in advance care planning behaviors. Journal of Hospice \& Palliative Nursing, 21(1), 54-60. doi: https:// doi.org/10.1097/NJH.0000000000000487

Senior Access Points of Larimer County. (2020). Larimer Advance Care Planning Team. Retrieved from http://senioraccesslarimer.colostate.edu/ advanced-care-planning-team/

Sudore, R. L., Stewart, A. L., Knight, S. J., McMahan, R. D., Feuz, M., Miao, Y., \& Barnes, D. E. (2013). Development and validation of a questionnaire to detect behavior change in multiple advance care planning behaviors. PLoS One, 8(9), 1-8. doi: https://doi.org/10.1371/journal. pone. 0072465

Thoelke, G. R. (2018). Millennials musing about advance care planning (Master's thesis, Miami University). Ohio Library and Information Network. Retrieved from http://rave.ohiolink.edu/ etdc/view?acc_num=miami1533295054008494

Tripken, J. L., \& Elrod, C. S. (2018). Young adults' perspectives on advance care planning. American Journal of Hospice and Palliative Medicine, 35(4), 627-634. doi: https://doi. org/10.1177/1049909117727456

University of Maryland. (2020). Parents. Retrieved from https://health.umd.edu/home/parents

University of Minnesota. (2020). Health care directive workshop. Retrieved from https:// extension.umn.edu/health-education/ health-care-directive-workshop

University of Missouri. (2020). Advance directives and surrogate decision making. Retrieved from https://medicine.missouri.edu/ centers-institutes-labs/health-ethics/faq/ advance-directives

Vader, A. M., Walters, S. T., Roudsari, B., \& Nguyen, N. (2011). Where do college students get health information? Believability and use of health information sources. Health Promotion Practice, 12(5), 713-722. doi: https://doi. org/10.1177/1524839910369995

Virginia Commonwealth University. (2020). Virginia advance medical directive. Retrieved from https://massey.vcu. edu/patient-care/rights-responsibilities/ virginia-advance-medical-directive/

Wiener, L., Ballard, E., Brennan, T., Battles, H., Martinez, P., \& Pao, M. (2010). How I wish to be remembered: The use of an advance care planning document in adolescent and young adult populations. Journal of Palliative Medicine, 11(10), 1309-1313. doi: https://doi.org/10.1089/ jpm.2008.0126

Wiener, L., Zadeh, S., Battles, H., Baird, K., Ballard, E., Osherow, J., \& Pao, M. (2012). Allowing adolescents and young adults to plan their end-of-life care. Pediatrics, 130(5), 897-905. doi: https://doi. org/10.1542/peds.2012-0663 
Wiener, L., Zadeh, S., Wexler, L. H., \& Pao, M. (2013). When silence is not golden: Engaging adolescents and young adults in discussions around end-of-life care choices. Pediatric Blood \& Cancer, 60(5):715-718. doi: https://doi.org/10.1002/ pbc. 24490

Woodlen, J., \& Bakken, S. (2016). Engaging patients with advance directives using an information visualization approach. Journal of Gerontological Nursing, 42(1), 16-20. doi: https://doi. org/10.3928/00989134-20150804-63.

Zadeh, S., Pao, M., \& Wiener, L. (2014). Opening end-of-life discussions: How to introduce Voicing My CHOiCESTM, an advance care planning guide for adolescents and young adults. Palliative \& Supportive Care, 13(3), 591-599. doi: https:// doi.org/10.1017/S1478951514000054 